\title{
PENGEMBANGAN SISTEM INFORMASI ADMINISTRASI AKADEMIK DENGAN RANCANGAN MODUL PROGRAM MENGGUNAKAN BAHASA PEMROGRAMAN BERORIENTASI OBJEK
}

\author{
Muhammad Siddik ${ }^{1}$, Azrai Sirait ${ }^{2}$ \\ ${ }^{1}$ Jurusan Teknik Informatika, STIKOM Pelita Indonesia, ${ }^{2}$ Jurusan Teknik Informatika, Fakultas Teknik UNA \\ E-mail: ${ }^{1}$ muhammdsiddk77@gmail.com, ${ }^{2}$ azray@una.ac.id
}

\begin{abstract}
Stephen Komputer Pekanbaru in processing the academic administration data, it's still being saved in a difference location and still not being organized. So, it's become a weakness, which is need a lot of time to present an information. Computer Technology that being used to present the information still can't running optimaly, so the system that already exist need to be improve, by take an advantage from a sophisticated computer technology to support the academic activity for example in speed, report form, accuracy, data security, always having an up to date data and also in data correction. The information system that being program with object-oriented programming language can help in programming the data that being related with education data. This information system can running optimally, if the system activity being support by the value of distribution, that being given by the instructure tutor to the system exactly at the appointed time.
\end{abstract}

Key Word: Information system, Administration, Object-Oriented Programming Language

\section{Abstrak}

Stephen Komputer Pekanbaru dalam pengolahan data administrasi akademik masih tersimpan secara tersebar pada lokasi berbeda dan tidak terorganisasi dengan baik, sehingga memiliki kelemahan yaitu memerlukan waktu lebih lama dalam penyajian informasi. Teknologi komputer yang dipakai untuk menghasilkan informasi belum berjalan dengan optimal, sehingga sistem yang ada perlu dikembangkan dengan memanfaatkan kecanggihan teknologi komputer dalam menunjang aktifitas akademik seperti dalam hal kecepatan, bentuk laporan, ketelitian, keamanan data, pemutakhiran serta dalam mengup-date data. Sistem yang akan dirancang dengan bahasa pemrograman berorientasi objek dapat membantu di dalam pengolahan data-data yang berkenaan dengan data kependidikan. Sistem informasi ini bisa berjalan dengan optimal bila aktifitas sistem didukung dalampendistribusian nilai yang diberikan oleh instruktur pengajar ke sistem tepat pada waktu yang telah ditentukan.

Kata Kunci: Sistem Informasi, Administrasi, Bahasa Pemrograman Berorientasi Objek.

\section{PENDAHULUAN}

Stephen Komputer Pekanbaru merupakan salah satu lembaga kursus komputer profesi yang ada di kota pekanbaru, Dalam perjalanan Stephen Komputer Pekanbaru terus melakukan inovasi dimana program awal yang disajikan adalah program regular (kursus tiga bulan dan enam bulan). Namun berdasarkan permintaan pasar/bursa kerja maka sejak tahun 1993 dirancang suatu program - 1 tahun yang diberi nama Program Sistem Informasi.Stephen Komputer telah berhasil memperoleh kepercayaan masyarakat dan mendapatkan pengakuan dari berbagai dunia usaha. Hal ini terbukti dengan banyaknya dunia usaha/perusahaan yang memberikan kesempatan kepada Stephen Komputer untuk menyediakan tenaga kerja pada perusahaan mereka.

Penerapan TeknologiInformasi (TI) untuk menunjang Sistem Informasi (SI) yang ada di lembaga kurus Stephen Komputer Pekanbaru belum berjalan secara optimal dimana teknologi yang digunakan untuk menunjang aktifitas lembaga kursus tersebut masih menggunakan perangkat lunak yang 
masih tergolong Spread Sheet dalam mengolah data-data yang berkenaan dengan peserta didik, instruktur pengajar, materi pendidikan, Kartu Hasil Studi (KHS), transkrip nilai dan data alumni perserta didik, sehingga dalam hal pendistribusian informasi masih dirasakan sangat lambat disebabkan oleh data-data yang tersimpan masih tersebar pada media penyimpanan elektronik yang berbeda.

Proses pembelajaran yang dibutuhkan oleh pihak Stephen Komputer khususnya dibagian administrasi akademik Stephen Komputer Pekanbaru, semakin bertambahnya jumlah persertadidik yang masuk pada lembaga kursus ini dari tahun ketahun, pihak akademik membutuhkan suatu inovasi dalam pengembangan SI yang ada dengan cara optimalisasi penggunaan TI dengan pengembangan teknologi baik secara hardware maupun dengan pengembangan aplikasi software seperti halnya penerapan SI dengan memakai rancagan modul program menggunakan bahasa pemrograman berorientasi objek, sehingga diharapkan nantinya proses pencatatan data yang berkenaan dengan administrasi akademik seperti data peserta didik, instruktur pengajar, instruktur penasehat akademik, materi pendidikan, KHS, transkrip nilai dan data alumni, tersimpan dalam satu file master dengan menggunakan prinsip Transaction Processing System (TPS), sehingga dalam penyajian informasi dapat di pilah-pilah dan dikembangkan dalam bentuk laporan yang nantinya laporan ini dapat di distribusikan langsung ke peserta didik, instruktur dan pimpinan selaku pengambil keputusan,dengan kata lain penggunaan TI untuk penunjang dari pada SI Computer-Based Information System (CBIS)dapat diterapkan secara optimal.

\section{KAJIAN LITERATUR Sistem}

Sistem adalah suatu komponen yang saling berkerja sama untuk mencapai suatu tujuan. Fungsi sistem yang utama menerima masukan, mengolah masukan, dan menghasilkan keluaran. Sedangkan informasi adalah data yang diolah sehingga berguna untuk pembuatan keputusan (Wing, 2004)..

\section{Informasi}

Informasi adalah hasil pengolahan data sehingga menjadi bentuk yang penting bagi penerimanya dan mempunyai kegunaan sebagai dasar dalam pengambilan keputusan yang dapat dirasakan akibatnya secara langsung saat itu juga atau secara tidak langsung pada saat mendatang(Edhy, 2004).

\section{Pemrograman Berorientasi Objek (OOP)}

Pemrograman Berorientasi Objek (OOP)adalah suatu cara baru dalam berpikir serta berlogika dalam menghadapi masalahmasalah yang akan dicoba atasi dengan bantuan komputer, dimana setiap objek adalah entitas tunggal yang memiliki kombinasi struktur data dan fungsi tertentu. Sedangkan objek adalah orang, tempat, benda, kejadian, atau konsep-konsep yang ada di dunia nyata yang penting pada suatu aplikasi misalnya, objek sebuah benda seperti mesin, gedung, komputer, mobil dan sebagainya. Objek sebuah kejadian seperti pembayaran uang pendidikan, registrasi biodata siswa, membaca buku dan sebagainya. Dengan kata lain objek merupakan sesuatu yang dapat dilihat, disentuh, dirasakan, diraba, untuk mendapatkan manfaat (Andi, 2002)

\section{Administrasi Akademik}

Administrasi Akademik Secara sederhana administrasi berasal dari kata latin "add dan "ministro". Add mempunyai arti "kepada" dan ministro berarti "melayani". Secara bebas dapat diartikan bahwa administrasi itu merupakan pelayanan atau pengabdian terhadap subyek tertentu. Administrasi akademik atau administrasi pendidikan mengandung dua pokok yaitu administrasi dan pendidikan. Pendidikan merupakan suatu proses dari serangkaian tindakan yang menuju ke suatu hasil tertentu. Tindakan tersebut bisa saja suatu perbuatan yang tampak tetapi juga bisa tidak tampak. Dalam pendidikan itu terdapat dua jenis proses, yaitu proses pendidikan dan nonpendidikan sering juga disebut proses teknis sedangkan proses nonpendidikan sering disebut juga nonteknis. Administarasi tergolong proses nonteknis yang pada dasarnya berfungsi agar proses teknis berjalan mulus. Fungsi proses administrasi itu adalah merancang, mengatur, mengkoordinasikan, menyediakan fasilitas, mengarahkan, dan memperbaiki proses teknis. Sedangkan proses teknis itu merupakan proses 
yang secara langsung berkenalan dengan pendidikan itu sendiri seperti perencanaan, penilaian, pelaksanaan pengajaran, dan kurikulum. (Imam, 1979).

\section{METODOLOGI PENELITIAN}

Proses pengumpulan data dalam penelitianini dengan cara observasi secara langsung ke Stephen Komputer Pekanbaru, hal ini dimaksudkan agar memudahkan dalam melakukan perbandingan antara sistem yang lama dengan sistem baru yang akan dirancang. Analisa sistem merupakan penguraian dari suatu sistem yang utuh kedalam bagian komponen-komponennya dengan maksud untuk mengidentifikasi dan mengevaluasi permasalahan, hambatan yang terjadi dan kebutuhan yang diharapkan nantinya dapat diusulkan dalam perbaikan sistem yang ada.Alat analisisyang digunakan adalah diagramcontext sistem administrasi akademik yang akan diteliti. Data Flow Diagram (DFD) yang bertujuan membantu dalam berkomunikasi dengan sistem yang akan dirancang, untuk memahami sistem secara logika. DFD digunakan untuk mengambarkan suatu sistem yang telah ada atau sistem baru yang akan dikembangkan. Implementasiprogram menggunakan bahasa pemrograman berorientasi objekDelphi 7.0 dan database SQLServer 2000.

\section{HASIL DAN PEMBAHASAN}

\subsection{Aliran Sistem Informasi Administrasi} Akademik

Sebelum merancang sebuah sistem perlu adanya analisa atau gambaran mengenai sistem yang berjalan di suatu perusahaan, disini digambarkan sebuah aliran sistem informasi yang ada di lembaga kursus Stephen Komputer, hal ini dimaksudkan agar memudahkan dalam melakukan perbandingan antara sistem yang lama dengan sistem yang baru. Analisa sistem merupakan penguraian dari suatu sistem yang utuh kedalam bagian komponen-komponennya dengan maksud untuk identifikasi danevaluasi permasalahan, hambatan yang terjadi dan kebutuhan yang diharapkan nantinya dapat diusulkan dalam perbaikan sistem yang ada.

Pesrta didik yangsudah registrasiulang pihak administrasi akademik akan memprosesnya sebagai data pesrta didik aktif, untuk proses materi pendidikan, pesrta didik dan instruktur pengajar ini semua berkaitan dengan proses akademik yangnatinya pihak akademik menyiapkan materi pendidikan dari kurikulum yang disajikan persemesternya. Dokumen ini akan memberikan informasi bagi peserta didik, instrukturpengajar dan pihak akademik. peserta didik yang telah mengikuti proses belajar selama satu semester yang berisikan nilai akan diproses untuk menghasilkan transkrip nilai sementara, transkrip nilai akhir serta data kelulusan peserta didik. Semua dokumen pendidikan ini merupakan siklus dari proses belajar mengajar di lembaga kursus Stephen Komputer Pekanbaru proses pembelajaran diadakan setiap hari senin sampai dengan sabtu, sedangkan untuk ujian diadakan setiap satu semester. dokumen hasil ujian peserta didik langsung berhubungan dengan instruktur pengajar dan peserta didik karena di dalamnya berisikan nilai-nilai peserta didik.

\subsection{Perancangan Sistem Informasi Administrasi Akademik Stephen Komputer Pekanbaru}

Pada tahap analisa sistem informasi yang sedang berjalan context diagram sangat membantu dalam memahami aliran sistem informasi yang akan diteliti, karena context diagram bisa membantu untuk mendapat gambaran apakah sistem informasi yang diteliti pantas untuk dikembangkan atau tidak, isi dari context diagram ini merupakan cerita tentang aliran sistem informasi yang diteliti.

\subsubsection{Context Diagram}

Pada context diagram ini terdiri atas sebuah lambang proses dengan label 0 , dan diberi nama Sistem Informasi Akademik sesuai penamaannya, proses tersebut nantinya akan melakukan pemrosesan terhadap nilainilai input berupa file peserta didik, file instruktur pengajar, filemateri pendidikan, file nilai diolah untuk menghasilkan informasi berupa laporan pesrta didik aktif, laporan laporan transkrip nilai akhir, KHS, laporan kelulusan peserta didik, laporan instruktur pengajar. Proses tersebut berinteraksi dengan beberapa eksternal entity yang digambarkan dalam bentuk segi empat atau biasa disebut dengan source / sink (sumber / tujuan), yaitu, perserta didik, administrasi, instruktur pengajar, pimpinan.Aliran data dapat dilihat pada gambar 4.1 di bawah ini : 


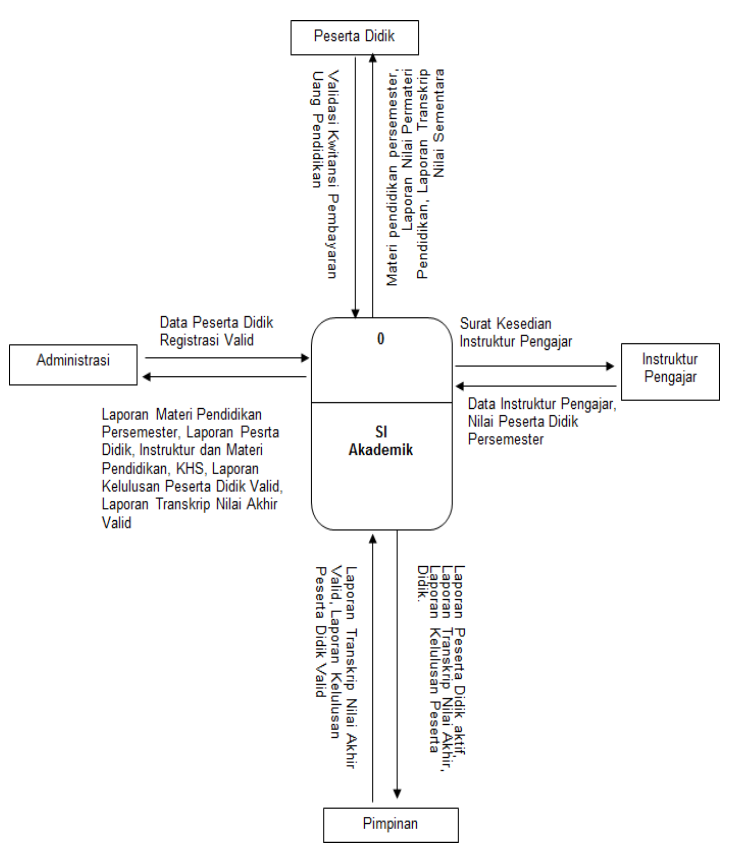

Gambar 4.1 Context Diagram yang diteliti dari Komponen Akademik

\subsubsection{Data Flow Diagram}

Proses dalam DFD 1.0, 2.0, 3.0, 4.0 masih mengambarkan aktifitas global dari sistem informasi yang akan dikembangkan / dirancang. Seperti dilihat pada proses 4.0 verifikasi dan transform di sini mungkin akan timbul pertanyaan bagaimana cara verifikasi dan transform, begitu pula dengan proses lainnya apa yang dilakukan saat proses updatedata store, access bandingkan kode, ataupun pada saat membuat informasi dan cetak laopran, dengan demikian gambar DFD di bawah ini harus di uraikan kembali kelevellevel berikutnya.

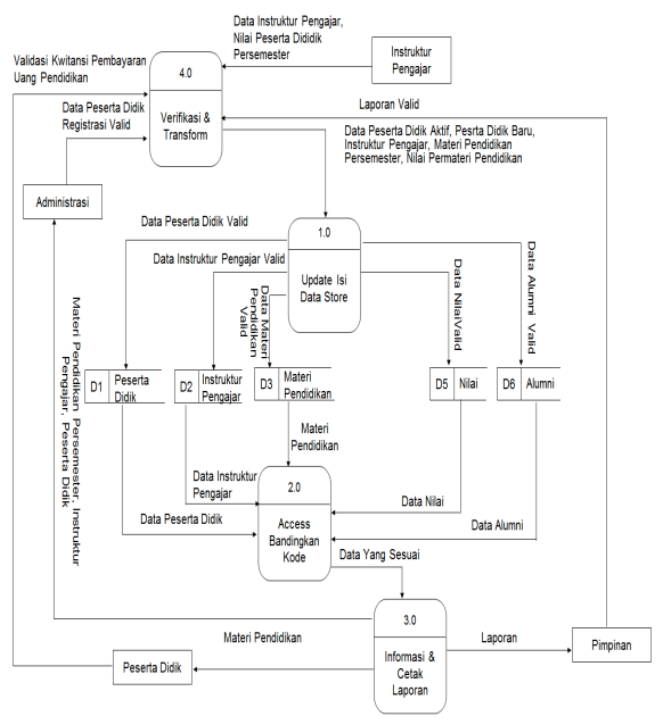

Gambar 4.2 Data Flow Diagram

\subsubsection{Entity Relationship Diagram}

Entity Relationship Diagram(ER-D) menunjukan hubungan antar file dalam database yang terdiri dari objek-objek yang nyata. Pada ER-Diagram ini terdapat enam buah file yang saling berhubungan dalam bentuk one to many, many to many dan one to one.

Entity peserta didik dan materi pendidikan, entity peserta didik dan instruktur pengajar, materi pendidikan dan instruktur pengajar, peserta didik dan nilai. Hubungan many to many dimana satu peserta didik memiliki satu atau lebih instruktur pengajar dan instruktur pengajar mempunyai satu atau banyak peserta didik, satu pesrta didik mengambil banyak materi pendidikan dan satu materi pendidikan diambil oleh satu banyak peserta didik, satu instruktur pengajar mengajar satu atau banyak materi pendidikan dan satu materi pendidikan diajar oleh satu atau banyak instruktur pengajar, satu instruktur pengajar memiliki satu atau banyak nilai dan satu nilai dimiliki oleh satu atau banyak peserta didik, untuk menjadi penghubung/key di field nis, field id_instruktur dan kode_materi untuk menghubungkan file peserta didik, file instruktur pengajar dan file materi pendidikan. Entitymateri pendidikan dan entity nilai, entitypeserta didik dan entity alumni mempunyai hubungan one to one dimana satu materi pendidikan mempunyai satu nilai dan satu nilai memiliki satu materi pendidikan, untuk menjadi kunci penghubung/key di field kode_materi dan field kode_materiforeign key untuk menghubungkan file mata kuliah dan file nilai. Satu peserta didik mempunyai satu data alumni dan satu data alumni dimiliki satu peserta didik, untuk penghubung / key di field nis dan field nisforeign key untuk menghubungkan filepeserta didik dan alumni.

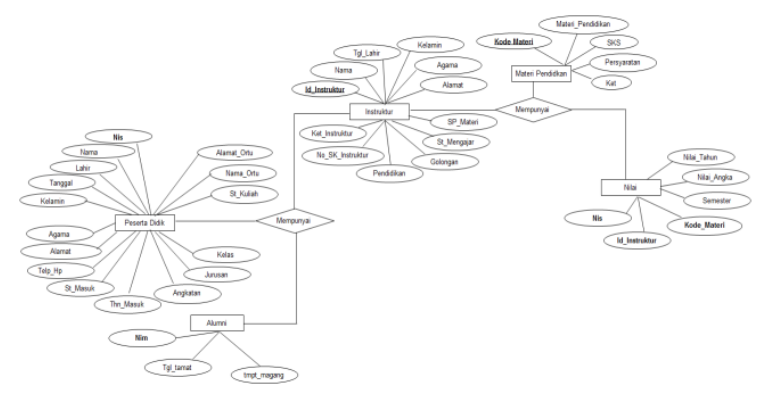

Gambar 4.3 Entity Relationship Diagram (ER-D) 


\subsubsection{Rancangan Output}

Untuk menghasilkan bentuk laporan yang dikehendaki, perlu dilakukan perancangan sistem terhadap bentuk outputnya, bentuk dari output tidaklah terlepas dari variabel input dari suatu sistem. Salah satu rancangan output dari sistem yang dibagun adalah laporan Kartu Hasil Studi (KHS) setiap persemester,merupakan bentuk output dari laporan hasil studi peserta didik untuk setiap semester.

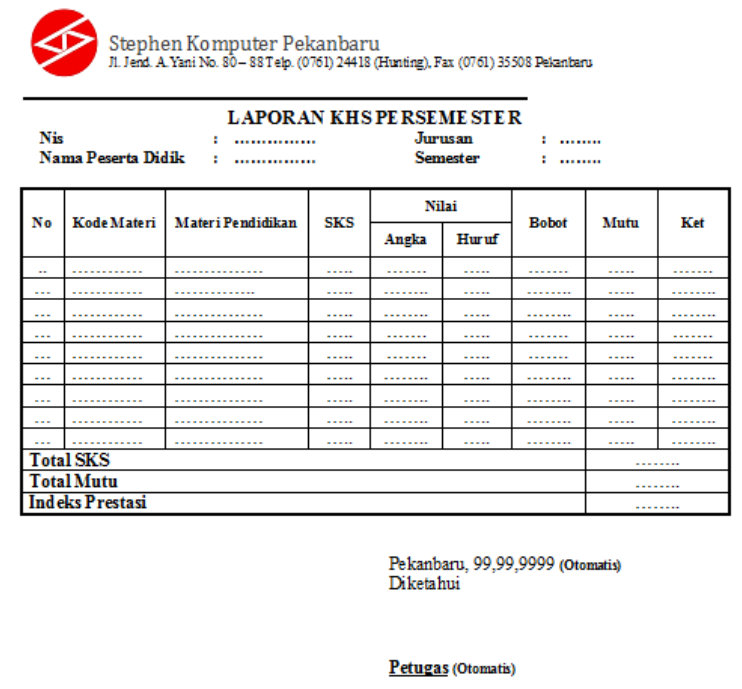

Gambar 4.4 Laporan KRS Persemester

\subsubsection{Rancangan Input}

Rancangan input merupakan bentuk tampilan layar di monitor yang berguna sebagai media interaksi antara user dengan sistem, proses ini terdiri dari proses pemasukan data kedalam sistem dan oleh sebab itu rancangan input harus dibuat sebaik mungkin agar lebih memudahkan user proses penginputan data. Rancangan input dari sistem yang di bagun ini terdiri dari entry peserta didik, entry instruktur pengajar dan entry materi pendidikan, sedang untuk proses transaksi terdapat pada entry nilai dan entry data alumni. Untuk proses kerahasian data dibuatkan suatu login untuk memasukan password user dan kalau password sesuai dengan database maka user berhak untuk memakai sistem ini. Untuk lebih jelasnya bisa dilihat dari beberapa gambar di bawah ini.

\section{a. Form Login}

Untuk proses kerahasian data dibuatkan suatu login untuk memasukan password user dan kalau password sesuai dengan file operator maka user dibawa masuk pada tampilan form menu utama dengan kata lain user berhak untuk memakai sistem ini dan apabila data tidak sesuai dengan file operator maka user bersangkutan tidak berhak untuk mengakses program.

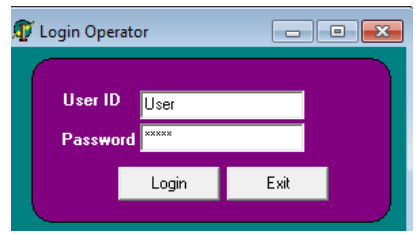

\section{Gambar 4.5Hasil Program Form}

\section{b. Form Menu Utama}

T Menu utama ini berisikan sub - sub menu yang berguna untuk memanggil formform yang berkenaan dengan program. Menu utama dibagi menjadi sub menu yaitu sub menuentry, sub menu transaksi, sub menu informasi, sub menu laporan dan sub menu exit. Dan masing-masing sub menu tersebut dibagi lagi mejadi beberapa sub bagian lagi.

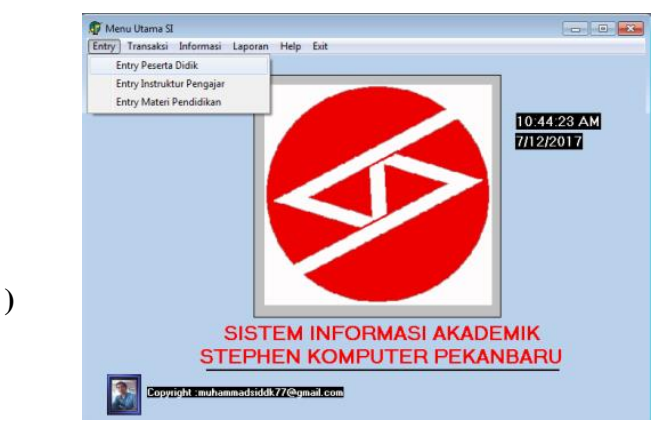

\section{Gambar 4.6 Hasil Program Form}

\section{c. Form Entry Data Perserta Didik}

Form ini berfungsi untuk pengentryan yang berkenaan dengan data pesrta didik yang akan mengikuti proses belajar mengajar di Stephen Komputer selama 1 tahun, sehingga data-data yang berkenaan dengan data peserta didik akan tersimpan di dalam database.

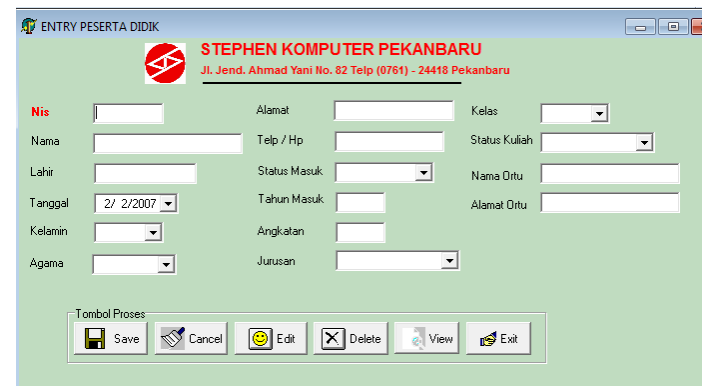

Gambar 4.7 Hasil Program Form Entry Data Peserta Didik 


\section{d. Form Entry Instruktur Pengajar}

Form ini berfungsi untuk pengentryan data instruktur pengajar yang akan mendidik di Stephen Komputer, sehingga data-data yang berkenaan dengan instruktur pengajar tersimpan di dalam database.

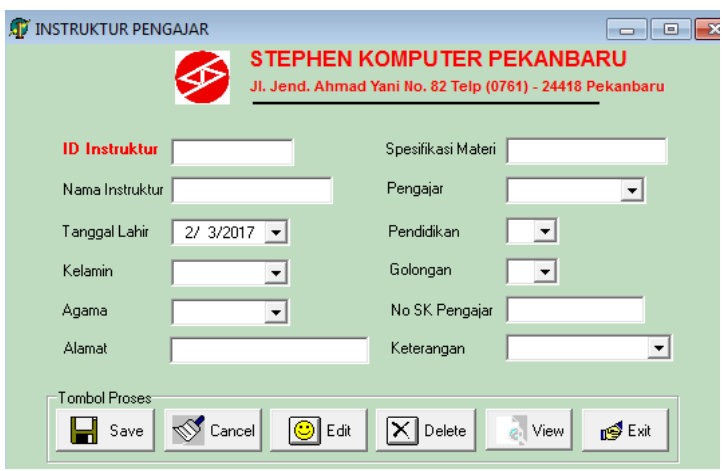

Gambar 4.8 Hasil Program Form Entry Data Instruktur Pengajar

\section{e. Form Entry Materi Pendidikan}

Form ini berfungsi untuk pengentryan yang berkenaan dengan materi pendidikan yang disajikan persemesternya, materi pendidikan suatu saat akan mengalami perubahan sesuai dengan permitaan dunia usaha. Pada form ini juga tersedia tombol edit data, dimana suatu saat materi ada perubahan akan bisa langsung diubah untuk disajikan pada semester tahun depan.

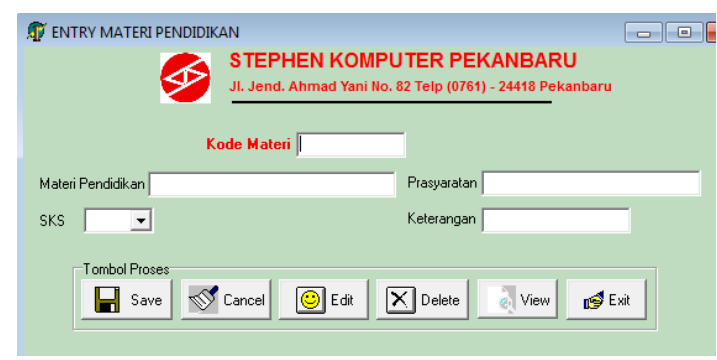

\section{Gambar 4.9 Hasil Program Form Entry Data Materi Pendidikan}

\section{f. Form Nilai}

Untuk pengentryan nilai pesertadidik dapat dilakukan apabila peserta didik, sudah mengikuti proses belajar mengajar di kelas serta sudah melaksanakan ujian semester sesuai dengan materi yang disajikan persemesternya oleh pihak akademik dan nilai peserta didik yang diserahkan oleh instruktur pengajar kepada pihak akademik sesuai tanggal dan waktu yang telah ditetapkan oleh pihak akademik.

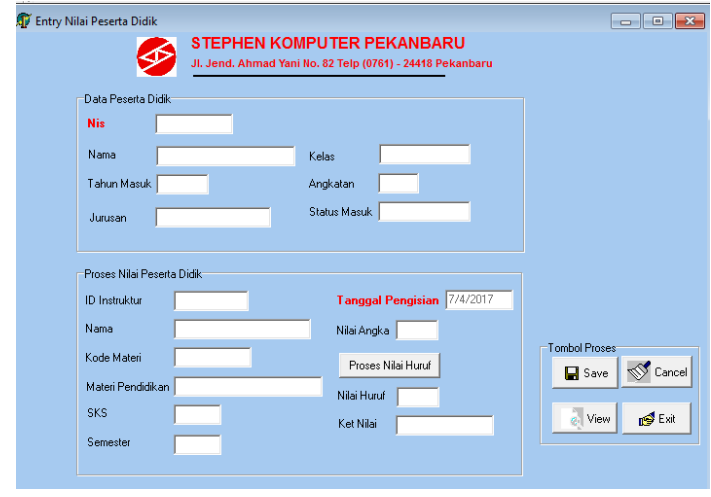

Gambar 4.10 Hasil Program Form Entry Data Nilai Peserta Didik

\section{g. Form Entry Data Alumni}

Form ini berfungsi untuk pengentryan data alumni Stephen Komputer yang sudah selesai mengikuti proses belajar mengajar selama 1 tahun dan dinyatakan lulus, sehingga data-data yang berkenaan dengan data alumni Stephen akan tersimpan nantinya di dalam suatu database.

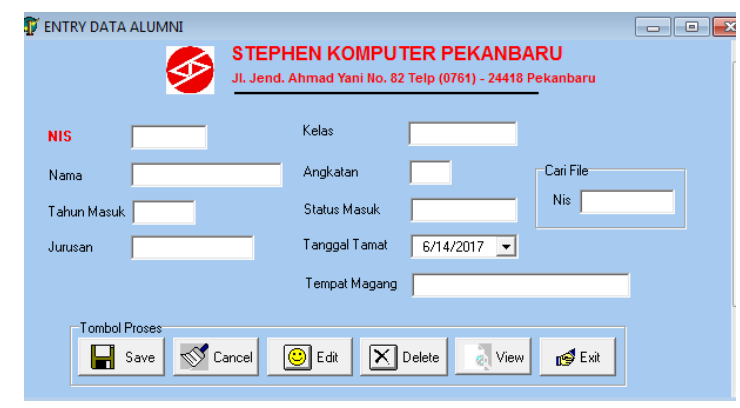

\section{Gambar 4.11 Hasil Program Form Entry Data Alumni}

\section{SIMPULAN}

Dengan adanya pengembangan sistem informasi akademik maka pendistribusian informasi yang cepat, tepat dan akurat seperti proses perhitungan, membandingkan, mengklasifikasikan, mengendalikan, atau mencari di penyimpanandapat dilakukan dengan menggunakan bahasa pemograman berorientasi objek serta didukung oleh datadata administrasi kependidikan seperti data peserta didik, instruktur pengajar, materi pendidikan, nilai yang tersimpan dalam satu file master di dalam media penyimpanan elektronik, sehingga file-file tersebut dapat dipanggil kembali untuk pembuatan laporanlaporan yang berfariasi, serta dalam pengoperasiannya pengguna sistem informasi dapat berinteraksi dengan komputer lebih 
mudah karena didukung dengan rancangan tampilan program yang interaktif.

\section{Saran}

Beberapa saran yang dapat diberikan kepada peneliti berikutnya agar sistem informasi ini menjadi lebih baik sebagai berikut:

1. Sistem informasi administrasi akademik Stephen Komputer Pekanbaru ini masih memerlukan pengembangan dan modifikasi terutama dalam pendistribusian data seperti data pengiriman nilai peserta didik oleh instruktur kebagian akademik bisa dikembangkan melalui web sehingga bisa lebih menghemat waktu.

2. Sistem informasi administrasi akademik yang ada masih berbasis desktop disarankan agar peneliti berikutnya bisa mengembangkan berbasis web, dengan tampilan program bisa lebih interaktif lagi, sehingga dalam pembuatan laporan dapat lebih berfariasi lagi dan penyebaran informasi akan lebih mudah dengan memanfaatkan teknologi internet.

\section{DAFTAR PUSTAKA}

Andi Nugroho, ST., MMSI, Analisa dan Perancangan Sistem Informasi dengan Metodologi Berorientasi Objek, Penerbit Informatika, Bandung, 2002

Edhy Susanta, Sistem Basis Data, Cetakan Pertama, Penerbit Graha Ilmu, Yogyakarta, 2004
Imam Sunoto, Perancangan Sistem Informasi Administrasi Akademik Berbasis Web, Program Studi Teknik Informatika, Fakultas Teknik, Matematika dan IPA Universitas Indraprasta PGRI. Faktor Exacta Vol. 5 No. 2: 146-155, ISSN: 1979 276X

Kusuma Wira Adi, Pemrograman Database dengan Delphi 6.0 dan SQL, Yogyakarta, 2002

Prof. Drs. Onong Uchjana Effendy, M.A, Sistem Informasi Manajemen, Cetakan keempat, Penerbit CV. Mandar Maju, Bandung, 1996

Drs. Wing Wahyu Winarno, Sistem Informasi Manajemen, UPP AMP YKPN, Yogyakarta, 2004 